\title{
Vinte anos de experiência de mentoria na Faculdade de Medicina da UFMG: desafios enfrentados e soluções propostas
}

\author{
Twenty years of mentoring at the UFMG Medical School: challenges faced and proposed solutions
}

\author{
Gilmar Tadeu de Azevedo Fidelis' ${ }^{1}$ (D) fidelisgilmar@gmail.com \\ Maria Mônica Freitas Ribeiro' 1 (1) mmonicaribe@gmail.com \\ Andreia Maria Camargos Rocha' (D) andreia@medicina.ufmg.br
}

\begin{abstract}
RESUMO
Introdução: A mentoria na Faculdade de Medicina da Universidade Federal de Minas Gerais se iniciou em 2001, em resposta a dificuldades emocionais dos estudantes, mas foi precedida por um projeto experimental, fundamentado no modelo de ajuda, em 1983.

Relato de experiência e discussão: Desde o seu início, muitos foram os desafios enfrentados, desde sua valorização e o entendimento de sua finalidade até a dificuldade de participação e manutenção dos mentores, bem como a ocorrência de uma mudança curricular nesse período. Para responder a esses desafios, algumas soluções foram propostas, como a educação continuada e a supervisão para os mentores, a criação da comentoria e da monitoria com o mentor júnior, e a busca de mentores voluntários. Novos desafios surgem a cada dia, mas a mentoria completou 20 anos de funcionamento no formato de disciplina obrigatória. Convive atualmente com dificuldades que a fragilizam e ameaçam, principalmente o fato de, embora institucional, ser dependente do esforço pessoal de um grupo de profissionais que nela acreditam.
\end{abstract}

Conclusão: A difusão do conceito de mentoring e de sua importância na formação médica, a valorização de professores que se interessam pela atividade de mentoria, com reconhecimento de seu trabalho pela instituição, e a formação continuada de mentores foram e continuam sendo medidas necessárias para o fortalecimento da mentoria.

Palavras-chave: Tutoria; Estudantes de Medicina; Educação de Graduação em Medicina.

\begin{abstract}
Introduction: Mentoring at the Federal University of Minas Gerais Medical School started in 2001 in response to emotional difficulties reported by students, but was preceded by an experimental project based on the aid model in 1983.

Experience report and discussion: Many challenges have been faced from the outset, from appreciating and understanding the purpose of the program, to ensuring the participation of and maintaining mentors, in addition to a curricular change that occurred in this period. In response to these challenges, some solutions have been proposed, such as continuing education and supervision for mentors, the creation of co-mentoring and undergraduate course monitoring, with the junior mentor and the search for volunteer mentors. New challenges arise every day, but the mentoring program is now twenty years' old as a compulsory subject of the medicine course. Mentoring currently has difficulties that weaken and threaten it, especially its dependence on the personal effort of a group of professionals who believe in it.
\end{abstract}

Conclusion: The diffusion of the concept of mentoring and its importance in medical training; the appreciation of teachers who are interested in the mentoring activity, with recognition of their work by the institution, and the continued training of mentors have been and continue to be necessary measures to strengthen mentoring.

Keywords: Mentoring; Medical Students; Medical Education; Undergraduate.

1 Universidade Federal de Minas Gerais, Belo Horizonte, Minas Gerais, Brasil.

Editora: Lia Marcia Cruz da Silveira

Recebido em 24/02/21; Aceito em 31/03/21.

Avaliado pelo processo de double blind review. 


\section{INTRODUÇÃO}

Embora a tutoria no formato de mentoring, como atividade obrigatória do curso de Medicina da Faculdade de Medicina da Universidade Federal de Minas Gerais (UFMG), tenha tido início em 2001, um projeto experimental, nos moldes de uma mentoria, já havia sido desenvolvido bem antes, em 1983.

Esse projeto, denominado Projeto Padrinho, era fundamentado no modelo de ajuda ${ }^{1,2}$ e surgiu das inquietações da professora Clara Feldman de Miranda, psicóloga que ministrava aulas sobre a relação médico-paciente no início do ciclo clínico, como forma de responder ao sofrimento psíquico dos estudantes. A partir de um curso de formação de padrinhos, ministrado a professores interessados e selecionados por demonstrarem empatia, bom relacionamento com os alunos e preocupação com a saúde mental deles, foram criados, por meio de convite aos estudantes, grupos de mentoria com dez a 12 alunos, inicialmente do quinto período (terceiro ano) do curso de Medicina, sob a supervisão dos professores/padrinhos. Era uma atividade não obrigatória e não reconhecida para integralização de créditos. O projeto funcionou até o início da década de 1990, quando se extinguiu, por falta de incentivo da faculdade, após a aposentadoria da professora responsável e de alguns dos padrinhos, sem que tivesse ocorrido uma renovação do grupo ${ }^{2}$.

Em 2000, com a evidência de problemas psíquicos entre estudantes que demandavam trancamento de matrícula, o Colegiado de Graduação do curso de Medicina iniciou uma discussão sobre a necessidade de oferecer apoio a esses discentes. Como o início do ciclo clínico já era identificado como um momento crítico na vida do estudante e como havia um módulo em uma disciplina interdepartamental que poderia ser utilizado para um suporte ao aluno, decidiu-se implantar a mentoria como módulo dessa disciplina obrigatória. Da mesma forma que no Projeto Padrinho, professores que se preocupavam com a saúde mental do estudante ou que já eram tutores informais eleitos pelos próprios alunos foram convidados a participar de um curso de capacitação no modelo de ajuda.

Assim, em 2001, a disciplina Tutoria, como é conhecida a atividade de mentoria na Faculdade Medicina da UFMG, teve seu início formal. Dispunha de duas horas de atividade semanal com um grupo de dez estudantes e um mentor, e não tinha programação previamente definida, o que deveria ser feito a partir das demandas surgidas em cada um dos grupos. O objetivo principal era constituir-se como um espaço de reflexão que permitisse o crescimento pessoal e a discussão sobre temas pertinentes à formação médica. Embora fosse um módulo de uma disciplina obrigatória, decidiu-se que não haveria uma avaliação formal, e, com relação ao discente, havia duas exigências: frequência mínima em $75 \%$ das aulas e um relatório final em que ele expressaria sua opinião sobre a mentoria. Da avaliação desse relatório, ajustes seriam feitos para o seu aprimoramento².

Em 2004, com a criação do Núcleo de Apoio Psicopedagógico ao Estudante da Faculdade de Medicina (Napem), a disciplina Tutoria passou a ser a ele integrada, como parte de um tripé constituído por atividades culturais (MedCine), de prevenção (mentoria) e de apoio psicopedagógico propriamente dito ${ }^{3}$. Logo a seguir, em 2005, a publicação do livro Tutoria: mentoring na formação médica forneceu ao projeto da UFMG referências teóricas, e teve início uma fecunda troca de experiências tanto nos congressos de educação médica quanto nos cursos realizados para os mentores e interessados na mentoria.

\section{RELATO DE EXPERIÊNCIA E DISCUSSÃO}

Já no seu início, muitos foram os desafios que surgiram. Como atividade interdepartamental, a disciplina dependia de carga horária de professores de vários departamentos. Entretanto, nem todos os departamentos se mostraram sensibilizados pela atividade, não disponibilizando carga horária de docentes, o que fez com que as configurações da estrutura original do corpo de mentores fossem mudando de acordo com o tempo e as demandas institucionais.

Assim, o excesso de carga horária exigido dos professores, as demandas específicas dos departamentos, a dificuldade de participação de docentes dos períodos iniciais no Instituto de Ciências Biológicas (distante fisicamente da Faculdade de Medicina), o não reconhecimento e/ou a não valorização da mentoria como uma atividade relevante na formação médica e a dificuldade para entender a tutoria como mentoring e não como tutoria exclusivamente acadêmica foram motivos que levaram ao desligamento de parte dos mentores um ano após terem feito a capacitação.

Diante dessas dificuldades, o quadro de mentores passou a sofrer grandes "baixas" sem tempo hábil para reposição de novos mentores aptos ou devidamente capacitados para assumir plenamente as turmas. Passou-se a usar, então, o recurso do profissional voluntário, que é uma atividade fundamentada na Lei n० 9.608, de 18 de fevereiro de 1998. Trata-se de atividade não remunerada, com finalidades assistenciais, educacionais, científicas, cívicas, culturais, recreativas ou tecnológicas, que não gera vínculo empregatício, nem obrigação de natureza trabalhista, previdenciária ou afim 5 .

Como primeiroautor destetexto, queépsicólogo, assumindo a coordenação da disciplina Tutoria, boa parte dos profissionais que chegaram como convidados tinha algum vínculo com a psicologia e/ou a psicanálise e suas várias configurações clínicas.

A chegada desses profissionais permitiu à mentoria sua sobrevivência, mesclando, em seu quadro de mentores, 
docentes da Faculdade de Medicina, docentes e profissionais de outras unidades, professores aposentados, mestrandos e doutorandos de áreas afins e outros convidados. Assim, nesses 20 anos, a heterogeneidade do grupo vem se configurando como um quadro permanente, formatando a identidade e gerando características específicas na mentoria da Faculdade de Medicina da UFMG.

As mudanças curriculares na Faculdade de Medicina também interferiram na disciplina Tutoria ao longo dos anos, exigindo adaptações e modificações. De módulo de uma disciplina, com 30 horas semestrais, passou a ser, com a reforma curricular implantada em 2014, uma disciplina própria, também com 30 horas $^{6}$. Como a mudança curricular mesclava o ciclo básico e o profissional e com a percepção de uma demanda significativa de auxílio psíquico pelos estudantes dos primeiros períodos, considerou-se que a disciplina Tutoria ficaria mais bem colocada no segundo período, ou seja, no início do curso médico. Nesse período, a mentoria poderia servir de suporte ao estudante na sua adaptação à vida universitária e também nas mudanças de estilo de vida geradas especialmente a partir da seleção feita pelo Sistema de Seleção Unificada (Sisu) do Ministério da Educação, que promoveu o aumento do número de alunos na faculdade que não eram de Belo Horizonte ou mesmo de Minas Gerais ${ }^{7}$.

Como disciplina interdepartamental vinculada ao Colegiado de Graduação, foi exigido, quando de sua criação, o compromisso dos departamentos com ela, o que, aparentemente, resolveria a questão de disponibilização de professores para ministrá-la.

Entretanto, esse cenário suposto não se concretizou, pois, apesarda posição de apoioàmentoria tanto da direção dafaculdade quanto do colegiado do curso médico, os departamentos, aos quais os professores estão diretamente vinculados, não têm cumprido seu compromisso de disponibilizar docentes para participação na disciplina Tutoria, interdepartamental, alegando falta de docentes para assumir a carga horária de outras disciplinas que são de responsabilidade exclusiva do departamento. Acrescente-se a isso o fato de que a mudança de período, embora bem justificada, implicou novos problemas que exigiram dos mentores novas abordagens. Para alguns, essa adaptação não foi satisfatória, o que gerou desistências. Assim, no ano de 2020, por exemplo, de 16 mentores vinculados à disciplina, apenas sete eram professores da Faculdade de Medicina da UFMG. É importante ressaltar ainda que, na maior parte das vezes, esses professores que se dispõem a ser mentores o fazem à custa de carga horária excedente à sua carga horária obrigatória, por acreditarem na proposta da mentoria.

Avaliações vêm sendo realizadas desde a implantação da disciplina de Tutoria, tendo sido publicados alguns dos resultados obtidos. Em 2013, a análise das respostas de um questionário preenchido por $81 \%(n=129)$ dos estudantes logo após o término da disciplina e por $51 \%(n=164)$ dos discentes do último ano do curso mostrou haver divergência na opinião deles sobre a relevância da mentoria. A obrigatoriedade da atividade e a inadequação de alguns mentores foram os fatores negativos mais salientados. O espaço aberto para discussão de temas relacionados à medicina que não os puramente técnicos e a orientação sobre aspectos angustiantes da formação médica, aliados à orientação acadêmica em momentos que exigem escolhas, foram destacados pelos estudantes que afirmaram sua relevância8 .

Martins et al. ${ }^{9}$, que utilizaram a abordagem fenomenológica em um estudo de relatórios feitos por estudantes que vivenciaram a mentoria, encontraram também diversidade de opiniões a respeito da relevância dessa ferramenta de aprendizagem. Se, para alguns, foi uma vivência significativa, tornou-se, para outros, objeto de sérias críticas. Martins et al. ${ }^{9}$ destacam "a necessidade do estabelecimento de um claro propósito para a atividade e do desenvolvimento dos tutores para uma boa prática na área, sobretudo, na difícil arte de condução de grupos" (p. 725).

Considerando a relevância do mentor para o desenvolvimento da atividade e também as queixas manifestadas pelos alunos nos processos avaliativos, busca-se constantemente o aprimoramento na formação e capacitação de novos mentores. Assim, em 2012, foi criada, a partir de experiências isoladas no passado recente da disciplina Tutoria, a categoria de comentor. A comentoria, presente até o momento, funciona como a introdução de um candidato a mentor nas atividades desenvolvidas na disciplina de Tutoria. Assim, o comentor trabalha em parceria com um mentor mais experiente, e, nesse processo, aquele pode se familiarizar com a atividade, aprender e desenvolver abordagens de grupo, participar do grupo e interagir com ele de acordo com seu desenvolvimento, sentir efetivamente a atividade de mentoria e, concomitantemente, avaliar se tem condições e/ou afinidade com essa área. Tem sido uma ideia muito bem acolhida, na medida em que não expõe desnecessariamente o candidato a mentor a uma experiência que pode ser desconfortável tanto para ele como para o grupo.

Muitas discussões e reflexões tiveram lugar nas reuniões de mentores, e alguns eventos foram realizados visando ao amadurecimento e desenvolvimento da mentoria, como:

- I Workshop da Tutoria - Organizando um Programa de Tutoria (Mentoring) para Estudantes de Medicina (2008).

- II Workshop da Tutoria: Mentoring na Formação Médica (2009).

- Videoconferência-Tutoria:USP/UFMG: da referência à interlocução (2009). 
- III Workshop da Tutoria - Teoria e Prática: Fundamentos Psicopedagógicos da Atividade de Tutoria (2010).

- Supervisão de Tutores Mentores: Como eu faço - $48^{\circ}$ Congresso Brasileiro de Educação Médica - Goiânia (2010).

- I Seminário da Tutoria/Faculdade de Medicina/ UFMG: A Formação Médica (2011).

Ainda com o propósito de aprimorar a formação de mentores, teve início, em 2012, a supervisão externa da atividade de mentoria feita por um professor do Departamento de Psicologia da Faculdade de Filosofia e Ciências Humanas da UFMG. As reuniões com periodicidade mensal e duração de duas horas perduraram até 2015. Já em 2012, por meio de reuniões com o coordenador da disciplina, os mentores que faziam parte do quadro relataram melhora do desempenho, tanto na solução de problemas quanto na dinâmica dos grupos. Essa atividade foi interrompida por dificuldades do supervisor e não foi retomada até o momento por falta de uma pessoa que possa assumi-la. Reuniões bimestrais são realizadas atualmente pelo coordenador e pelos mentores para discussão de dificuldades e troca de experiências.

Outra proposta desenvolvida no segundo semestre letivo de 2012 e presente até o momento foi a criação da monitoria da disciplina Tutoria (iniciação à docência), com mentores juniores selecionados a partir de parâmetros semelhantes aos de uma seleção para monitoria, porém considerando os aspectos e perfis inerentes a uma atividade de mentoria, já descritos. Para participar da seleção, o estudante já deve ter tido a experiência da mentoria e, idealmente, deve estar em períodos mais avançados do curso. A principal atividade dos monitores é acompanhar sistematicamente um mentor em suas atividades semanais com o grupo. Os mentores juniores, além da supervisão do mentor, têm reuniões bimestrais com o coordenador da disciplina para avaliação e compartilhamento de experiências.

Atualmente, cada grupo de mentoria conta com um ou dois mentores juniores. A experiência com os monitores na mentoria (mentores juniores) tem sido muito rica desde o seu início. A vivência do curso e a proximidade temporal dessas vivências com os alunos da disciplina trazem ganhos significativos para as discussões do grupo, independentemente de ser o mentor um professor da Faculdade de Medicina.

Apesar das limitações apresentadas neste relato, a mentoria na Faculdade de Medicina está ativa, com suas antigas e novas questões. São 16 turmas de disciplina obrigatória no segundo período do curso, cada uma delas com dez estudantes, um mentor, um comentor e um ou dois tutores juniores. Os mentores têm perfis variados, predominando no quadro atual os psicólogos voluntários.

\section{CONCLUSÃO}

A difusão para professores e estudantes do conceito de mentoring e de sua importância na formação médica, a valorização de docentes que se interessam pela atividade de mentoria, com reconhecimento de seu trabalho pela instituição, e a formação continuada de mentores foram e continuam sendo medidas necessárias para o fortalecimento da mentoria.

\section{CONTRIBUIÇÃO DOS AUTORES}

Todos os autores colaboraram igualmente na redação e revisão do artigo.

\section{CONFLITO DE INTERESSES}

Declaramos não haver conflito de interesses.

\section{FINANCIAMENTO}

Declaramos não haver financiamento.

\section{REFERÊNCIAS}

1. Miranda CF, Miranda ML. Construindo a relação de ajuda. Belo Horizonte: Crescer; 1983.

2. Fidélis GTA. A tutoria na Faculdade de Medicina da Universidade Federal de Minas Gerais: de um sonho necessário à construção. Rev Méd Minas Gerais 2014;24(4):525-34.

3. Faculdade de Medicina da UFMG. Núcleo de Apoio Psicopedagógico ao Estudante da Faculdade de Medicina [acesso em 19 fev 2021]. Disponível em: https://www.medicina.ufmg.br/napem/.

4. Bellodi PL, Martins MA. Tutoria: mentoring na formação médica. São Paulo: Casa do Psicólogo; 2005.

5. Brasil. Lei $n^{\circ} 9.608$, de 18 de fevereiro de 1998 . Dispõe sobre o serviço voluntário e dá outras providências [acesso em 19 fev 2021]. Disponível em: http://www.planalto.gov.br/ccivil_03/leis/19608compilado.htm.

6. Universidade Federal de Minas Gerais. Centro de graduação da Faculdade de Medicina. Disciplinas da Faculdade de Medicina [acesso em $19 \mathrm{fev}$ 2021]. Disponível em: https://www.medicina.ufmg.br/cegrad/medicina/ disciplinas/.

7. Nonato BF. Lei de Cotas e Sisu: análise dos processos de escolha dos cursos superiores e do perfil dos estudantes da UFMG antes e após as mudanças na forma de acesso às instituições federais [tese]. Belo Horizonte: Universidade Federal de Minas Gerais; 2018.

8. Ribeiro MMF, Martins AF, Fidelis GTA, Goulart GC, Molinari LC, Tavares EC, et al. Tutoria em escola médica: avaliação por discentes após seu término e ao final do curso. Rev Bras Educ Med. 2013;37(4):509-14.

9. Martins AF, Bellodi PL. Mentoring: uma vivência de humanização e desenvolvimento no curso médico. Interface (Botucatu). 2016;20(58):715-26. 